Rev. Bras. Saúde Prod. Anim., Salvador, v.16, n.4, p.948-957 out../dez.., 2015 http://www.rbspa.ufba.br ISSN 15199940

\title{
Cultivo da tilápia do Nilo Oreochromis niloticus em sistema de bioflocos com diferentes densidades de estocagem
}

\author{
Culture of the Nile tilapia "Oreochromis niloticus" in biofloc system with different \\ stocking densities
}
LIMA, Eduardo Cesar Rodrigues de ${ }^{1 *}$; SOUZA, Rafael Liano de ${ }^{1}$; WAMBACH, Xélen Faria $^{1}$; SILVA, Ugo Lima ${ }^{1}$; CORREIA, Eudes de Souza ${ }^{2}$

\footnotetext{
${ }^{1}$ Universidade Federal Rural de Pernambuco, Programa de Pós-Graduação em Recursos Pesqueiros e Aquicultura, Recife, Pernambuco, Brasil.

${ }^{2}$ Universidade Federal Rural de Pernambuco, Departamento de Pesca e Aquicultura, Recife, Pernambuco, Brasil.

*Endereço para correspondência: educesar19@gmail.com
}

\section{RESUMO}

Objetivou-se com este trabalho avaliar a qualidade da água e o desempenho zootécnico da tilápia do Nilo (Oreochromis niloticus) cultivada em sistema de bioflocos sob diferentes densidades de estocagem. O experimento foi conduzido na Estação de Aquicultura da Universidade Federal Rural de Pernambuco, Brasil, durante 128 dias. Peixes de 123,0 $\pm 0,6 \mathrm{~g}$ foram estocados em 12 tanques circulares $(800 \mathrm{~L}) \mathrm{em}$ um delineamento inteiramente casualizado com três tratamentos (D15, D30 e D45, correspondendo as densidades de 15,30 e 45 peixes. $\mathrm{m}^{-3}$ ) e quatro repetições. Entre as variáveis de qualidade de água, o oxigênio dissolvido teve efeito significativo $(\mathrm{P} \leq 0,05)$ entre as densidades, com a menor concentração $\left(3,97 \mathrm{mg} \mathrm{O} \cdot \mathrm{L}^{-1}\right)$ na maior densidade testada (45 peixes. $\left.\mathrm{m}^{-3}\right)$. A amônia total apresentou diferença estatística $(\mathrm{P} \leq 0,05)$ entre o tratamento D15 e os demais; e o nitrito, entre a densidade de 15 e 45 peixes. $\mathrm{m}^{-3}$, porém ambos numa relação diretamente proporcional com o aumento da densidade de estocagem, apresentando maiores concentrações médias de 2,56 e 3,26 mg. $\mathrm{L}^{-1}$ de amônia e nitrito, respectivamente, na densidade de 45 peixes. $\mathrm{m}^{-3}$. O desempenho zootécnico, no tratamento D45 apresentou melhor resultado, com produtividade de $16,6 \mathrm{Kg} . \mathrm{m}^{-3}$, com diferença significativa entre os tratamentos $(\mathrm{P} \leq 0,05)$. A sobrevivência foi superior a $90 \%$ nas três densidades testadas. A tecnologia de bioflocos pode ser empregada no cultivo intensivo da tilápia do Nilo $O$. niloticus na fase de engorda, utilizandose densidades de estocagem de 45 peixes. $\mathrm{m}^{-3}$.

Palavras-chave: piscicultura, produtividade, sistema intensivo, melaço

\section{SUMARY}

This work aimed to evaluate the water quality and the growth performance of Nile tilapia (Oreochromis niloticus) cultured in bioflocs system with different stocking densities. The experiment was conducted at the Aquaculture Station of the Federal Rural University of Pernambuco, Brazil, during 128 days. Fish $123.0 \pm 0.6 \mathrm{~g}$ were stocked in twelve $800 \mathrm{~L}$ circular tanks in a completely randomized design with three treatments (D15, D30 and $\mathrm{D} 45$, related to densities of 15,30 and 45 fish. $\mathrm{m}^{-3}$ ) and four replicates. Among water quality variables, dissolved oxygen had a significant effect $(\mathrm{P} \leq 0.05) \quad$ between the densities, with the lowest concentration (3.97 $\mathrm{mg} \mathrm{O}_{2} \cdot \mathrm{L}^{-1}$ ) for the highest tested density (45 fish. $\left.\mathrm{m}^{-3}\right)$. The total ammonia present statistical difference between the D15 and the others; and also, the nitrite, between density 15 and 45 fish. $\mathrm{m}^{-3}$, but both at a directly proportional relationship with the increasing of stocking density, showing higher average concentrations of 2.56 and $3.26 \mathrm{mg} . \mathrm{L}^{-1}\left(\mathrm{NH}_{3}+\mathrm{NH}_{4}\right.$ and $\mathrm{NO}_{2}$, respectively), in 45 density fish. $\mathrm{m}^{-3}$. The growth performance in the 45 fish. $\mathrm{m}^{-3}$ density showed the best results, with yield of $16.6 \mathrm{~kg} \cdot \mathrm{m}^{-3}$, with significant difference between treatments $(\mathrm{P} \leq 0.05)$. Survival was higher than $90 \%$ at the three tested densities. Bioflocs technology can be employed in intensive culture of Nile tilapia $O$. niloticus in the growout phase, using stocking densities up to 45 fish.m ${ }^{-3}$.

Keywords: fish farming, yield, intensive system, molasses 


\section{INTRODUÇ̃̃O}

Os sistemas de produção adotados na criação das tilápias são classificados em extensivo, semi-intensivo, intensivo e super-intensivo. A busca por uma maior produtividade deve-se considerar boas práticas de manejo, a fim de não tornar a atividade aquícola uma possível fonte de impacto ambiental. Assim, é de extrema importância a implantação de sistemas de produção sustentáveis, capazes de minimizar os danos ao meio ambiente, destacando-se os sistemas de cultivos fechados (COLT et al., 2006). Dentre esses, o sistema de bioflocos vêm se popularizando nos últimos anos e foi recentemente considerado como uma técnica mais sustentável por não realizar trocas de água ao longo do cultivo (AVNIMELECH, 2007; AZIM \& LITTLE, 2008; CRAB et al., 2009). O princípio da tecnologia de bioflocos é reciclar nutrientes através de uma elevada relação carbono/nitrogênio na água, a fim de estimular o crescimento de bactérias heterotróficas que convertem amônia em biomassa microbiana, que suplementa a alimentação dos organismos cultivados (AVNIMELECH, 1999; 2007).

As tilápias estão perfeitamente adaptadas ao sistema de bioflocos. A capacidade de se alimentar por filtração da água, permite a absorção dos bioflocos em suspensão, e por ser um peixe robusto e de rápido crescimento, está adaptado a sistemas bem adensados (AVNIMELECH, 2011). A tecnologia de bioflocos permite a utilização de altas densidades de estocagem e elevadas produtividades (10 a 40Kg.m ${ }^{-3}$ ) (AVNIMELECH, 2005).

Vários estudos têm sido realizados para avaliar os efeitos da densidade de estocagem no cultivo de tilápias, entre eles, Rakocy et al. (2004) cultivando tilápias em tanques circulares de $200 \mathrm{~m}^{3}$, numa densidade de 20 e 25 peixes. $\mathrm{m}^{-3}$ e com aeração constante, observaram uma produção 28 vezes maior que as obtidas em viveiros não aerados $\left(14,40 \mathrm{Kg} \cdot \mathrm{m}^{-3}\right)$. Widanarni et al. (2012) avaliaram o desempenho da tilápia vermelha Oreochromis sp. sob diferentes densidades $\left(25,50,100\right.$ peixes. $\left.\mathrm{m}^{-3}\right) \mathrm{e}$ obtiveram os melhores índices de sobrevivência utilizando o sistema de bioflocos, quando comparados ao tratamento controle, sem adição de carbono.

Assim, os bons resultados observados indicam que a utilização do sistema de bioflocos é aplicável para as tilápias. Desta forma, o estudo objetivou avaliar o efeito da densidade de estocagem no crescimento e na qualidade da água no cultivo de tilápia do Nilo (O. niloticus) em sistema de bioflocos.

\section{MATERIAL E MÉTODOS}

O cultivo foi desenvolvido na Estação de Aquicultura da Universidade Federal Rural de Pernambuco (UFRPE), no período de maio a setembro de 2012, totalizando 128 dias. Foram utilizados doze tanques circulares de fibra de vidro com capacidade de 1000L e volume útil de $800 \mathrm{~L}$, localizados em área externa com iluminação natural e cobertos com telas para evitar o escape dos animais. $\mathrm{O}$ experimento dispôs de um sistema de aeração mantido por um compressor radial $(7,5 \mathrm{CV})$, possibilitando aeração individual, com dois pontos de saída de ar, ambos com pedras porosas. Os tanques foram abastecidos com $800 \mathrm{~L}$ de água com bioflocos, oriunda de um cultivo anterior com duração de 67 dias. Para manutenção do sistema heterotrófico fez-se uso do melaço líquido, como fonte de carbono, respeitando-se a relação Carbono e 
Rev. Bras. Saúde Prod. Anim., Salvador, v.16, n.4, p.948-957 out../dez.., 2015 http://www.rbspa.ufba.br ISSN 15199940

Nitrogênio (6:1) de acordo com Samocha et al. (2007).

Alevinos de $O$. niloticus, linhagem Chitralada, revertidos sexualmente à machos, foram adquiridos numa piscicultura comercial e posteriormente mantidos em viveiros escavados numa densidade de 8 peixes. $\mathrm{m}^{-2}$ até atingirem o peso médio de $123,0 \pm 0,6 \mathrm{~g}$. Ao serem transferidos para os tanques de cultivo com bioflocos, adotou-se um delineamento experimental inteiramente casualizado com três tratamentos e quatro repetições, avaliando as densidades de estocagem de 15 (D15), 30 (D30) e 45 (D45) peixes.m ${ }^{-3}$.

Os peixes foram alimentados com ração comercial extrusada (Pirá 32, Guabi ${ }^{\circledR}$, Brasil) cujos níveis de garantia são $8 \%$ de umidade, $32 \%$ de proteína bruta, $6,5 \%$ de extrato etéreo, $10 \%$ de matéria mineral e $7 \%$ de fibras, a qual foi ofertada quatro vezes ao dia, às 08:00, 11:00, 14:00 e 17:00h. Foram realizadas biometrias semanais, com o objetivo de avaliar o crescimento dos peixes e ajustar a quantidade de ração a ser fornecida de acordo com a biomassa ( $\mathrm{g}$ ) de cada tanque. Este acompanhamento foi realizado pela pesagem de $10 \%$ da população de cada unidade experimental, utilizando balança digital $( \pm 0,01 \mathrm{~g})$, realizada antes da primeira alimentação do dia. A taxa diária de alimentação durante o cultivo variou de 5,0 a $2,5 \%$ do peso vivo.

Ao final do experimento, todos os peixes foram quantificados e pesados para determinação do desempenho zootécnico por meio das seguintes variáveis e respectivas fórmulas: Peso Final; Ganho de Peso (GP = peso médio final - peso médio inicial); Ganho de Peso diário (GPD = GP.tempo de cultivo em dias $\left.{ }^{-1}\right)$; Taxa de crescimento específico (TCE $=100 .(\mathrm{ln}$ do peso final - $\ln$ do peso inicial).(tempo de cultivo) $\left.^{-1}\right)$; Taxa de sobrevivência
$(\mathrm{S}=$ 100.(população final.população inicial $\left.^{-1}\right)$; Fator de Conversão Alimentar (FCA $=$ Quantidade de alimento fornecido.ganho de biomassa $^{-1}$ ); Produtividade

(Prod $=$ (biomassa final.volume do tanque $\left.\left.^{-1}\right) \cdot 1000^{-1}\right)$.

A qualidade da água foi mensurada durante todo período do estudo com base nas variáveis físicas e químicas: temperatura $\left({ }^{\circ} \mathrm{C}\right)$, oxigênio dissolvido $\left(\mathrm{mg} . \mathrm{L}^{-1}\right)$ e $\mathrm{pH}$, mensuradas duas vezes ao dia, às 7:00 e 16:00 horas, utilizando sonda multiparâmetro (YSI 556, YSI Inc., Yellow Springs, OH, USA).

Para as análises de nitrito $\left(\mathrm{NO}_{2}{ }^{-}\right)$, amônia total $\left(\mathrm{NH}_{4}+\mathrm{NH}_{3}\right)$ e alcalinidade total, amostras de água foram coletadas semanalmente e os resultados foram obtidos por meio da utilização de métodos colorimétricos. Em seguida foi adicionado aos tanques de cultivo bicarbonato de sódio para manter a alcalinidade em torno de $150 \mathrm{mg} . \mathrm{L}^{-1}$ de $\mathrm{CaCO}_{3}$ (EBELING et al., 2006).

O volume dos sólidos sedimentáveis $\left(\mathrm{mL} . \mathrm{L}^{-1}\right)$ foi analisado semanalmente, onde amostras de um litro de água de cada unidade experimental foram transferidas para cones de Imhoff e após 40 minutos de descanso, o volume correspondente a estes sólidos foram medidos, objetivando quantificar o incremento do biofloco ao longo do cultivo. Adotou-se como nível ideal de sólidos sedimentáveis em torno de 20mL.L ${ }^{-1}$ (AVNIMELECH, 2011). O controle desse nível foi realizado através da utilização de tanques de sedimentação conectados aos tanques de cultivo, adaptado de Ray et al. (2010).

Os resultados foram avaliados utilizando o software Biostat 5.8.3, adotando o teste de análise de variância (ANOVA) para determinar possíveis diferenças entre os tratamentos, ao nível de significância de 0,05. Quando 
Rev. Bras. Saúde Prod. Anim., Salvador, v.16, n.4, p.948-957 out../dez.., 2015 http://www.rbspa.ufba.br ISSN 15199940

necessário, a análise de variância foi completada pelo Teste de Tukey (comparação de médias), ao nível de probabilidade de $5 \%$.

\section{RESULTADOS E DISCUSSÃO}

A avaliação do crescimento foi realizada por meio das variáveis de rendimento do cultivo apresentadas na Tabela 1. O peso final, ganho de peso, ganho de peso diário, fator de conversão alimentar e taxa de crescimento específico não apresentaram diferença significativa entre as três densidades testadas $(\mathrm{P}>0,05)$. Entretanto, a sobrevivência, a biomassa final e a produtividade foram diferentes $(\mathrm{P} \leq 0,05)$ entre os tratamentos.
O peso médio final dos peixes variou de 400,10 a 426,28g, e não diferiu significativamente entre as densidades testadas $(\mathrm{P}>0,05)$. No entanto, alguns autores como Widanarni et al. (2012) ao estudarem a aplicação do sistema de bioflocos no cultivo da tilápia vermelha (Oreochromis sp.) nas densidades de 25,50 e 100 peixes. $\mathrm{m}^{-3}$, encontraram o menor peso final de $129,03 \mathrm{~g}$ na densidade de 100 peixes.m ${ }^{-3}$. Azim \& Little (2008) observaram que tilápias do Nilo (O. niloticus) estocadas na densidade de $12 \mathrm{Kg} \cdot \mathrm{m}^{-3}$ tiveram pesos individuais $10 \%$ maiores nos tratamentos com bioflocos (BFT) e esses contribuíram com $45 \%$ para o ganho de peso individual, bem como para a produção de peixes.

Tabela 1. Valores médios ( \pm desvio padrão) do desempenho zootécnico da tilápia do Nilo Oreochromis niloticus, cultivadas sob diferentes densidades em sistema de bioflocos

\begin{tabular}{lccc}
\hline \multirow{2}{*}{ Variáveis } & \multicolumn{3}{c}{ Tratamentos } \\
\cline { 2 - 4 } & D15 & D30 & D45 \\
\hline Peso final $(\mathrm{g})$ & $400,1 \pm 32,31^{\mathrm{a}}$ & $426,28 \pm 13,33^{\mathrm{a}}$ & $404,37 \pm 49,26^{\mathrm{a}}$ \\
Ganho de peso (g) & $276,90 \pm 32,29^{\mathrm{a}}$ & $302,51 \pm 12,03^{\mathrm{a}}$ & $281,48 \pm 51,55^{\mathrm{a}}$ \\
GPD (g.dia $\left.{ }^{-1}\right)$ & $2,16 \pm 0,25^{\mathrm{a}}$ & $2,36 \pm 0,09^{\mathrm{a}}$ & $2,20 \pm 0,40^{\mathrm{a}}$ \\
TCE $\left(\% \cdot\right.$ dia $\left.^{-1}\right)$ & $0,92 \pm 0,07^{\mathrm{a}}$ & $0,97 \pm 0,02^{\mathrm{a}}$ & $0,93 \pm 0,11^{\mathrm{a}}$ \\
Sobrevivência (\%) & $100,00 \pm 0,00^{\mathrm{a}}$ & $98,96 \pm 2,08^{\mathrm{ab}}$ & $90,97 \pm 6,94^{\mathrm{b}}$ \\
FCA & $1,62 \pm 0,17^{\mathrm{a}}$ & $1,38 \pm 0,16^{\mathrm{a}}$ & $1,58 \pm 0,19^{\mathrm{a}}$ \\
Biomassa final $(\mathrm{Kg})$ & $4,80 \pm 0,39^{\mathrm{c}}$ & $10,12 \pm 0,34^{\mathrm{b}}$ & $13,26 \pm 2,02^{\mathrm{a}}$ \\
Produtividade $\left(\mathrm{Kg} \cdot \mathrm{m}^{-3}\right)$ & $6,00 \pm 0,48^{\mathrm{c}}$ & $12,65 \pm 0,42^{\mathrm{b}}$ & $16,57 \pm 2,53^{\mathrm{a}}$ \\
\hline
\end{tabular}

Letras distintas na mesma linha indicam diferença significativa $(\mathrm{P}<0,05)$ entre os tratamentos. D15, D30 e D45 - Densidade de 15, 30 e 45 peixes. $\mathrm{m}^{-3}$, respectivamente. GPD - Ganho médio de peso diário, TCE Taxa de crescimento específico, FCA - Fator de conversão alimentar.

O ganho de peso diário (GPD) variou entre 2,16 e 2,36g.dia ${ }^{-1}$, e não apresentou diferença significativa entre os tratamentos $(\mathrm{P}>0,05)$. A taxa de crescimento específico (TCE) variou de 0,92 a $0,97 \% \cdot d i a^{-1}$ e não apresentou diferença significativa entre as densidades $(\mathrm{P}>0,05)$. Ayroza et al. (2011) avaliou diferentes densidades de estocagem $(100,200,300$ e 400 peixes. $\mathrm{m}^{-3}$ ), para juvenis de tilápia do Nilo em tanques-rede e, observaram uma diminuição no ganho de peso diário com aumento da densidade de 
estocagem. Para o mesmo sistema de cultivo (tanques-rede), Araújo et al. (2010) avaliaram as densidades 100 , 150 e 200 peixes. ${ }^{-3}$ para tilápia do Nilo (O. niloticus), e foi notado a mesma tendência registrada por Ayroza et al. (2011). Ao utilizar a tecnologia de bioflocos, Widanarni et al. (2012) observaram o mesmo resultado, quando avaliaram o desempenho da tilápia vermelha (Oreochromis sp.) nas densidades de 25,50 e 100 peixes. $\mathrm{m}^{-3}$, obtendo o menor ganho médio de peso diário de $0,52 \mathrm{~g} \cdot \mathrm{dia}^{-1}$ na densidade de 100 peixes. $\mathrm{m}^{-3}$. No entanto, no presente estudo, as densidades de estocagem não influenciaram o ganho de peso diário dos peixes ao longo do cultivo.

No presente trabalho, a sobrevivência apresentou um percentual acima de 90\% nas densidades de estocagem estudadas, onde foi constatada diferença significativa $(\mathrm{P} \leq 0,05)$ entre os tratamentos $\mathrm{D} 15$ e D45, observando-se uma relação inversamente proporcional ao aumento da densidade de estocagem, onde na maior densidade avaliada (45 peixes. $\mathrm{m}^{-3}$ ) obteve-se uma menor sobrevivência $(90,97 \%)$. Isto pode ser atribuído às maiores concentrações de amônia $\left(2,56 \mathrm{mg} . \mathrm{L}^{-1}\right)$ e nitrito $\left(3,26 \mathrm{mg} . \mathrm{L}^{-}\right.$ $\left.{ }^{1}\right)$, e à menor concentração de oxigênio dissolvido $\left(3,97 \mathrm{mg} . \mathrm{L}^{-1}\right)$ encontrada nesse tratamento.

A biomassa final entre os tratamentos variou de 4,80 a $13,26 \mathrm{Kg}$, resultando numa produtividade variando entre 6,00 e $16,57 \mathrm{Kg} \cdot \mathrm{m}^{-3}$. Ambas as variáveis exibiram diferença significativa entre os tratamentos $(\mathrm{P} \leq 0,05)$, e apresentou uma relação diretamente proporcional a densidade de estocagem. Rakocy et al. (2004) cultivando tilápias em tanques circulares de $200 \mathrm{~m}^{3}$ com bioflocos, numa densidade de 20 e 25 peixes. $\mathrm{m}^{-3}$, obtiveram uma produtividade de 14,40 e $13,70 \mathrm{Kg} \cdot \mathrm{m}^{-3}$, respectivamente, que foi semelhante ao encontrado no presente estudo. De acordo com Avnimelech
(2005), uma produtividade de 10 a $40 \mathrm{Kg} \cdot \mathrm{m}^{-3}$ pode ser obtida na tilapicultura com bioflocos.

O fator de conversão alimentar (FCA) esteve entre 1,38 e 1,62, e não apresentou diferença significativa $(\mathrm{P}>0,05)$ entre as densidades testadas. Segundo Ono \& Kubitza (2003), a expectativa de conversão alimentar de tilápias em sistemas de cultivo intensivo como o de tanques-rede é de 1,4 a 1,8. Os valores do FCA obtidos no presente estudo foram melhores que os encontrados por Azim \& Little (2008) utilizando sistema de bioflocos no cultivo de tilápia $(3,44 \mathrm{e}$ 3,51 ), e corroboram com os estudos de Avnimelech (2007), que afirma que os bioflocos contribuem significativamente para o crescimento dos peixes. Os flocos microbianos constituídos por bactérias, zooplâncton, protozoários e microalgas agregados à matéria orgânica, contém aproximadamente $61 \%$ de proteína bruta. Além disso, os peixes cultivados no meio com bioflocos se alimentam continuamente, uma vez que a produção microbiana é um processo contínuo (AVNIMELECH, 2009).

Os resultados das variáveis físicas e químicas da água estão apresentados na Tabela 2. Durante o período experimental a temperatura e o $\mathrm{pH}$ apresentaram médias de $26,80^{\circ} \mathrm{C}$ e 7,82 , respectivamente e não apresentaram diferença significativa entre os tratamentos $(\mathrm{P}>0,05)$. A temperatura mínima da água registrada foi de $23,5^{\circ} \mathrm{C}$, estando ligeiramente abaixo do conforto térmico ideal para tilápia, porém $\mathrm{o}$ consumo alimentar não foi afetado. De acordo com Kubitza (2011) para um ótimo crescimento da tilápia a faixa de conforto térmico ideal está entre $27 \mathrm{e}$ $32^{\circ} \mathrm{C}$ e o $\mathrm{pH}$ deve ser mantido entre $6,00 \mathrm{e}$ 8,50 .

A concentração de oxigênio dissolvido nos tanques de cultivo variou de 2,00 a 6,00mg. $\mathrm{L}^{-1}$, com média de $4,37 \mathrm{mg} . \mathrm{L}^{-1}$. 
Rev. Bras. Saúde Prod. Anim., Salvador, v.16, n.4, p.948-957 out../dez.., 2015 http://www.rbspa.ufba.br ISSN 15199940

Para os tratamentos D15, D30 e D45, as respectivas médias foram de 4,96, 4,20 e $3,97 \mathrm{mg} . \mathrm{L}^{-1}$, apresentando diferença significativa entre os mesmos $(\mathrm{P} \leq 0,05)$. Também foi observada uma relação inversamente proporcional entre a concentração de oxigênio dissolvido e a densidade de estocagem. Os resultados encontrados por Widanarni et al. (2012) corroboram com o presente estudo. Eles registraram um declínio do oxigênio dissolvido com o aumento da densidade de estocagem. Este fato é atribuído ao consumo de oxigênio pela maior biomassa de peixes, biomassa microbiana e pelo processo de oxidação da matéria orgânica acumulada nos tanques de cultivo.

Tabela 2. Valores médios ( \pm desvio padrão) das variáveis físico-químicas de qualidade da água durante o cultivo da tilápia do Nilo Oreochromis niloticus, submetida a diferentes densidades em sistema de bioflocos

\begin{tabular}{|c|c|c|c|}
\hline \multirow[b]{2}{*}{ Variáveis } & \multicolumn{3}{|c|}{ Tratamentos } \\
\hline & D15 & D30 & D45 \\
\hline Temperatura $\left({ }^{\circ} \mathrm{C}\right)$ & $26,73 \pm 1,42^{\mathrm{a}}$ & $26,81 \pm 1,42^{\mathrm{a}}$ & $26,87 \pm 1,52^{\mathrm{a}}$ \\
\hline Alcalinidade total $\left(\mathrm{mg} \cdot \mathrm{L}^{-1} \mathrm{CaCO}_{3}\right)$ & $105,33 \pm 25,94^{\mathrm{a}}$ & $82,68 \pm 26,66^{\mathrm{b}}$ & $68,63 \pm 16,95^{\mathrm{c}}$ \\
\hline $\mathrm{pH}$ & $7,87 \pm 0,33^{\mathrm{a}}$ & $7,79 \pm 0,27^{\mathrm{a}}$ & $7,80 \pm 0,29^{\mathrm{a}}$ \\
\hline Oxigênio dissolvido (mg. $\left.\mathrm{L}^{-1}\right)$ & $4,96 \pm 0,54^{\mathrm{a}}$ & $4,20 \pm 0,73^{\mathrm{b}}$ & $3,97 \pm 0,76^{\mathrm{c}}$ \\
\hline Amônia total $\left(\mathrm{mg} \cdot \mathrm{L}^{-1} \mathrm{NH}_{3}+\mathrm{NH}_{4}\right)$ & $0,48 \pm 0,40^{\mathrm{a}}$ & $1,71 \pm 2,24^{\mathrm{b}}$ & $2,56 \pm 3,59^{b}$ \\
\hline Nitrito $\left(\mathrm{mg} \cdot \mathrm{L}^{-1} \mathrm{NO}_{2}\right)$ & $0,78 \pm 0,57^{\mathrm{a}}$ & $1,66 \pm 1,66^{\mathrm{ab}}$ & $3,26 \pm 8,66^{\mathrm{b}}$ \\
\hline Sólidos sedimentáveis $\left(\mathrm{mL} \cdot \mathrm{L}^{-1}\right)$ & $23,95 \pm 12,83^{\mathrm{a}}$ & $27,14 \pm 11,84^{\mathrm{ab}}$ & $28,82 \pm 11,95^{\mathrm{b}}$ \\
\hline
\end{tabular}

Letras distintas na mesma linha indicam diferença significativa $(\mathrm{P}<0,05)$.

A alcalinidade total variou de 15 a 160mg.L ${ }^{-1}$ de $\mathrm{CaCO}_{3}$ (Figura 1), apresentando diferença significativa entre os tratamentos $(\mathrm{P} \leq 0,05)$. Azim \& Little (2008) avaliando a qualidade da água em sistema com e sem bioflocos, obtiveram alcalinidade total variando de 8 a $250 \mathrm{mg} . \mathrm{L}^{-1}$ de $\mathrm{CaCO}_{3}$ no tratamento com biofloco, confirmando que as oscilações observadas nesta variável é um fato comum, quando utilizado $\mathrm{o}$ sistema de bioflocos no cultivo de tilápia. As menores médias foram observadas nos tratamentos D30 e D45 (82,68 e 68,63mg. $\mathrm{L}^{-1}$ de $\mathrm{CaCO}_{3}$, respectivamente), provavelmente devido ao consumo de carbono pelas bactérias heterotróficas. Segundo Ebeling et al. (2006) o consumo da alcalinidade por bactérias heterotróficas, como fonte de carbono $\left(3,57 \mathrm{~g} \cdot \mathrm{g}^{-1} \mathrm{NAT}\right)$, ainda que de forma moderada, é um aspecto importante em sistemas com troca de água limitada, sendo necessário a adição de carbonatos para manter a alcalinidade em níveis aceitáveis.

O volume dos sólidos sedimentáveis esteve diretamente relacionado ao aumento das densidades de cultivo. Os valores médios encontrados nos tratamentos D15 e D45 foram, respectivamente, de 23,95 e $28,82 \mathrm{~mL} \cdot \mathrm{L}^{-1}$, apresentando diferença significativa entre as densidades estudadas $(\mathrm{P} \leq 0,05)$. Ressalta-se que, durante os 128 dias de cultivo, o volume destes sólidos foi mantido em uma concentração em torno de $20 \mathrm{~mL} . \mathrm{L}^{-1}$ fazendo uso dos tanques de sedimentação. No entanto, deve-se ressaltar que esse equipamento não possui uma precisão na remoção dos sólidos. Widanarni et al. (2012) estudando a aplicação do sistema de bioflocos no cultivo de tilápia em 
Rev. Bras. Saúde Prod. Anim., Salvador, v.16, n.4, p.948-957 out../dez.., 2015 http://www.rbspa.ufba.br ISSN 15199940

diferentes densidades de estocagem, registraram um volume dos sólidos sedimentáveis de 113 e $147 \mathrm{~mL} . \mathrm{L}^{-1}$, respectivamente, para as densidades de 50 e 100 peixes.m ${ }^{-3}$. De acordo com
Avnimelech (2011) o volume dos sólidos sedimentáveis, para o cultivo de tilápias com sistema de bioflocos, deve manter-se entre 5 e $50 \mathrm{~mL} . \mathrm{L}^{-1}$.

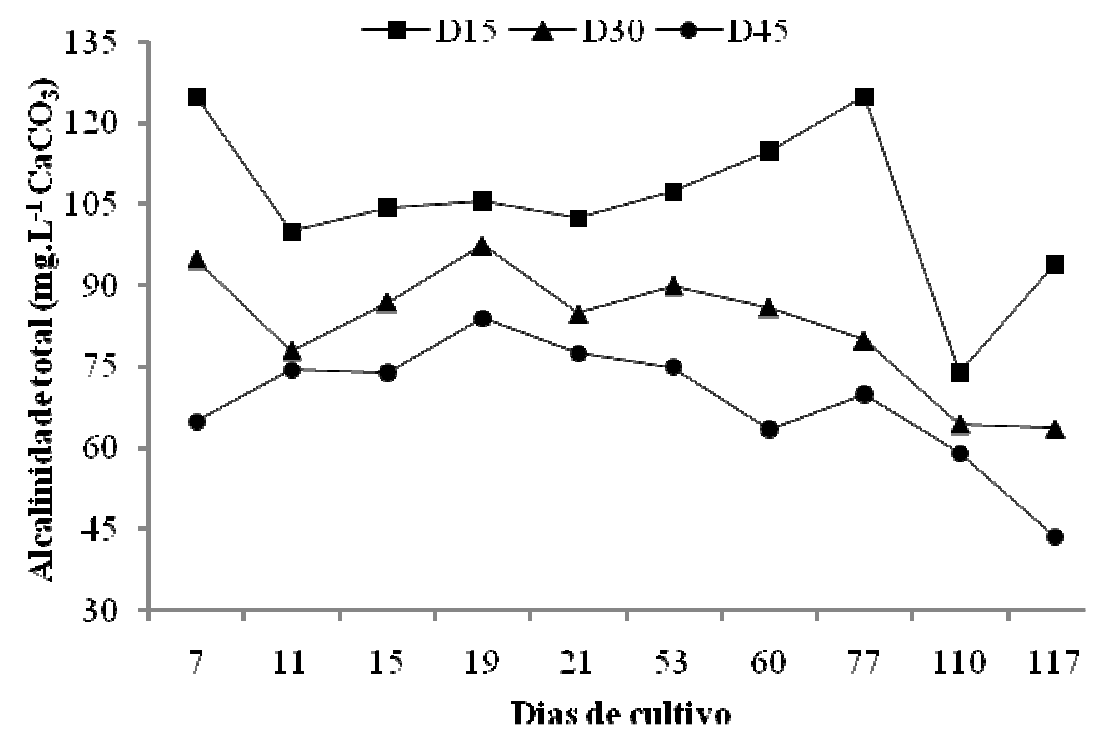

Figura 1. Variação da alcalinidade total durante o cultivo da tilápia do Nilo, submetida a diferentes densidades de estocagem em sistema de bioflocos

Em relação aos compostos nitrogenados, a amônia total $\left(\mathrm{NH}_{3}+\right.$ $\left.\mathrm{NH}_{4}^{+}\right)$e o nitrito $\left(\mathrm{NO}_{2}^{-}\right)$permaneceram em níveis aceitáveis durante o período experimental. Entretanto, ambos apresentaram diferença significativa entre os tratamentos $(\mathrm{P} \leq 0,05)$, mostrando maiores concentrações médias de amônia total $\left(2,56 \mathrm{mg} . \mathrm{L}^{-1}\right)$ e de nitrito $\left(3,26 \mathrm{mg} . \mathrm{L}^{-}\right.$ $\left.{ }^{1}\right)$ na densidade de 45 peixes. ${ }^{-3}$, provavelmente devido à maior biomassa de peixes e ao consequente acúmulo e decomposição da matéria orgânica nessa densidade.

A variação da amônia total foi de 0,25 a $8,44 \mathrm{mg} . \mathrm{L}^{-1}$ (Figura 2A) e do nitrito foi de 0,29 a $16,19 \mathrm{mg} . \mathrm{L}^{-1}$ (Figura 2B). A concentração máxima da amônia total $\left(\mathrm{NH}_{3}+\mathrm{NH}_{4}\right)$ foi de $8,44 \mathrm{mg} . \mathrm{L}^{-1}$, equivalente a $0,37 \mathrm{mg} . \mathrm{L}^{-1}$ de $\mathrm{N}-\mathrm{NH}_{3}$, estando abaixo da concentração letal
( $\left.\mathrm{LC}_{50}\right)$ encontrada por El-Sherif (2008), ao expor alevinos de tilápia do Nilo por 48 horas a $7,1 \mathrm{mg} . \mathrm{L}^{-1}$ de $\mathrm{N}-\mathrm{NH}_{3}$. Em relação ao nitrito, a concentração máxima encontrada esteve abaixo do reportado por Yanbo et al. (2006). Estes autores ao testarem a toxicidade do nitrito em tilápias, observaram que concentrações acima de $28,1 \mathrm{mg}$ de $\mathrm{NO}_{2}{ }^{-}$ . $\mathrm{L}^{-1}$ podem causar $50 \%$ de mortalidade após 96h de exposição.

Luo et al. (2014) registraram oscilações com valores máximos de compostos nitrogenados, principalmente amônia (60mg.L $\mathrm{L}^{-1}$ NAT $\sim 75 \mathrm{mg} . \mathrm{L}^{-1}$ amônia total) e nitrito $\left(119 \mathrm{mg} . \mathrm{L}^{-1} \quad \mathrm{~N}-\mathrm{NO}_{2} \sim\right.$ $390,9 \mathrm{mg} . \mathrm{L}^{-1} \mathrm{NO}_{2}$ ) em cultivo de tilápia em sistema de bioflocos. Essas oscilações são comuns nesse sistema de cultivo, principalmente, neste caso, quando se utilizou bioflocos de um 
Rev. Bras. Saúde Prod. Anim., Salvador, v.16, n.4, p.948-957 out../dez.., 2015 http://www.rbspa.ufba.br ISSN 15199940

cultivo anterior, cuja variação pode ocorrer simplesmente por uma queda de oxigênio quando da aplicação de grandes quantidades de melaço ou ração. Deve-se ressaltar que Correia et al. (2014) relataram que as bactérias oxidantes de nitrito (ex. Nitrobacter) são lentas no seu desenvolvimento quando comparadas com as bactérias oxidantes da amônia (ex. Nitrosomonas). Em comparação com o presente trabalho, as concentrações de amônia e nitrito foram muito aquém dos registros de Luo et al. (2014). Dessa forma constata-se a resistência da tilápia Oreochromis niloticus à toxidez dos compostos nitrogenados na presença de bioflocos.
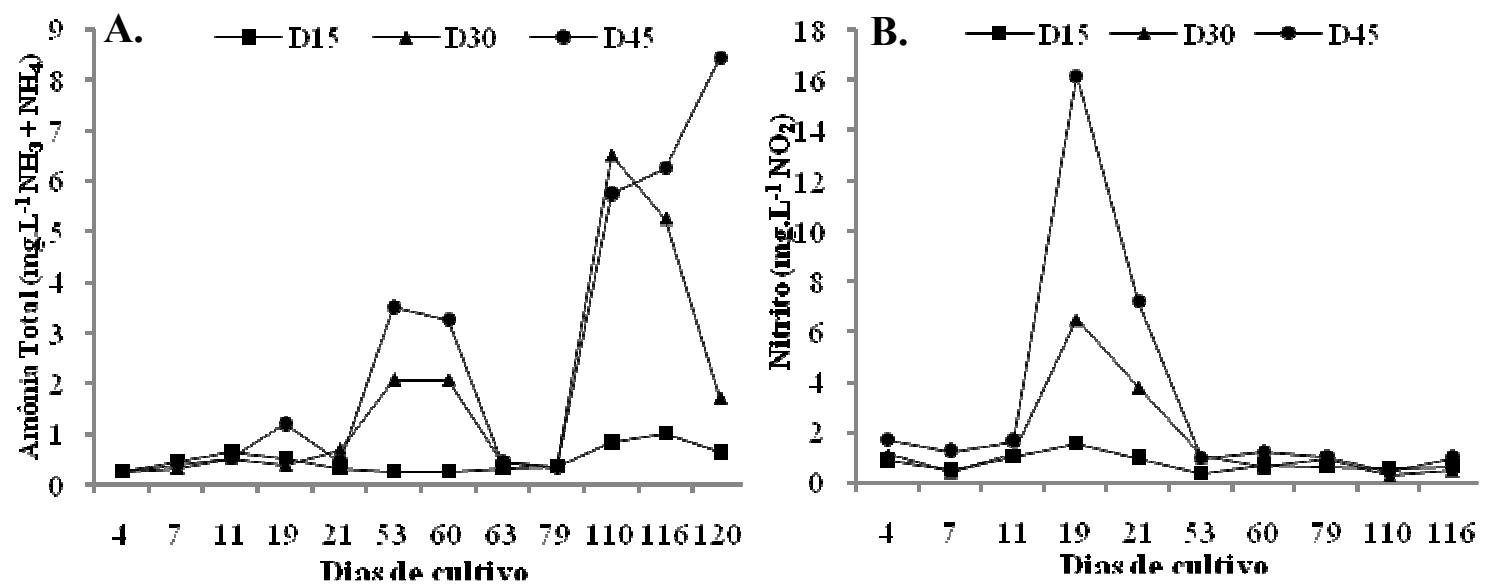

Figura 2. Concentrações de amônia total (A) e de nitrito (B) registradas durante o cultivo da tilápia do Nilo Oreochromis niloticus, submetida a diferentes densidades em sistema de bioflocos

Com os dados obtidos no trabalho podese concluir que a densidade de estocagem de 45 peixes. $\mathrm{m}^{-3}$ apresentou a melhor resposta, uma vez que foi possível atingir uma produtividade de $16,57 \mathrm{Kg} \cdot \mathrm{m}^{-3}$ e sobrevivência de $91 \%$, além da obtenção de peixes maiores que 400g em 128 dias de cultivo. O sistema de cultivo com bioflocos pode ser empregado no cultivo intensivo de tilápia do Nilo (Oreochromis niloticus) na fase de engorda. Sugere-se a realização de outros trabalhos com o uso de densidades de estocagem superiores às empregadas no presente estudo, utilizando tanques de cultivo com maiores dimensões, visando otimizar a produtividade em larga escala.

\section{AGRADECIMENTOS}

À Estação de Aquicultura Continental Prof. Johei Koike da Universidade Federal Rural de Pernambuco por disponibilizar o espaço físico para execução do estudo. À GUABI pelo fornecimento das rações utilizadas no experimento. À Fundação de Amparo à Ciência e Tecnologia do Estado de Pernambuco (FACEPE), ao Conselho Nacional de Desenvolvimento Científico e Tecnológico (CNPq) e à Coordenação de Aperfeiçoamento de Pessoal de Nivel Superior (CAPES) e ao Ministério da Educação (MEC/SeSu) pelas bolsas de estudo. 
Rev. Bras. Saúde Prod. Anim., Salvador, v.16, n.4, p.948-957 out../dez.., 2015 http://www.rbspa.ufba.br ISSN 15199940

\section{REFERÊNCIAS}

AVNIMELECH, Y. Carbon/nitrogen ratio as a control element in aquaculture systems. Aquaculture, v.176, p.227-235, 1999.

AVNIMELECH, Y. Tilapia harvest microbial flocs in active suspension research pond. Global Aquaculture Advocate, p.57-58 October 2005.

AVNIMELECH, Y. Feeding with microbial flocs by tilapia in minimal discharge bio-flocs technology ponds. Aquaculture, v.264, p.140-147, 2007.

\section{AVNIMELECH, Y. Biofloc}

Technology: a pratical guide book. Baton Rouge, Louisiana: World Aquaculture Society, 2009. 182p.

AVNIMELECH, Y. Tilapia production using biofloc technology - saving water, waste recycling improves economics.

Global Aquaculture Advocate, p.66-68 May/June 2011.

ARAUJO, G.S.; RODRIGUES, J.A.G.; SILVA, J.W.A. DA; FARIAS, W.R.L. Cultivo da tilápia do Nilo em tanquesrede circulares em diferentes densidades de estocagem. Bioscience Journal, v.26, n.3, p.428-434, 2010.

AYROZA, L.M.S.; ROMAGOSA, E.; AYROZA, D.M.M.R.; SCORVO FILHO, J.D.; SALLES, F.A. Custos e rentabilidade da produção de juvenis de tilápia do Nilo em tanques-rede utilizando-se diferentes densidades de estocagem. Revista Brasileira de Zootecnia, v.40, n.2, p.231-239, 2011.

AZIM, M.E.; LITTLE, D.C. The biofloc technology (BFT) in indoor tanks: Water quality, biofloc composition, and growth and welfare of Nile tilapia (Oreochromis niloticus). Aquaculture, v.283, p.29-35, 2008.
COLT, J.; LAMOUREUX, J.; PATTERSON, R.; ROGERS, G. Reporting standards for biofilter performance studies. Aquacultural Engineering, v.34, n.3, p.377-388, 2006.

CORREIA, E.S.; WILKENFELD, J.S.; MORRIS, T.C.; WEI, L.; PRANGNELL, D.I; SAMOCHA, T.M. Intensive nursery production of the Pacific white shrimp Litopenaeus vannamei using two commercial feeds with high and low protein content in a biofloc-dominated system. Aquacultural Engineering, v.59, p.4854, 2014.

CRAB, R.; KOCHVA, M.; VERSTRAETE, W.; AVNIMELECH, Y. Bio-flocs technology application in over-wintering of tilapia. Aquacultural Engineering, v.40, n.3, p.105-112, 2009.

EBELING, J.M.; TIMMONS, M.B.; BISOGNI, J.J. Engineering analysis of the stoichiometry of photoautotrophic, autotrophic, and heterotrophic removal of ammonia-nitrogen in aquaculture systems. Aquaculture, v.257, p.346358, 2006.

EL-SHERIF, M.S.; FEKY, E.; AMAL, $\mathrm{M}$. Effect of ammonia on Nile tilapia (O. niloticus) performance and some hematological and histological measures. In: INTERNATIONAL SYMPOSIUM ON TILAPIA IN AQUACULTURE, 8., 2008, Cairo, Egypt. Proceedings... Cairo, Egypt, 2008. p.513-530.

KUBITZA, F. Tilápia: Tecnologia e planejamento na produção comercial. 2.ed. rev. ampl. Jundiaí: Acqua Supre Com. Suprim. Aquicultura, 2011. 316p. 
LUO, G.; GAO, Q.; WANG, C.; LIU, W.; SUN, D.; LI, L.; TAN, H. Growth, digestive activity, welfare, and partial cost-effectiveness of genetically improved farmed tilapia (Oreochromis niloticus) cultured in a recirculating aquaculture system and an indoor biofloc system. Aquaculture, v.422423, p.1-7, 2014.

ONO, E.A.; KUBITZA, F. Cultivo de peixes em tanques rede. 3 .ed. Jundiaí: E. Ono, 2003. 112p.

RAKOCY, J.E.; BAILEY, D.S.; THOMAN, E.S.; SHULTZ, R.C. Intensive tank culture of tilapia with a suspended, bacterial-based treatment process: new dimensions in farmed tilapia. IN: INTERNATIONAL SYMPOSIUM ON TILAPIA IN AQUACULTURE, 2004, MANILA, PHILIPPINES. Proceedings... MANILA, PHILIPPINES, 2004. v.6, p.584-596.

RAY, A.J.; LEWIS, B.L.; BROWDY, C.L.; LEFFLER, J.W. Suspended solids removal to improve shrimp (Litopenaeus vannamei) production and an evaluation of a plant-based feed in minimal-exchange, superintensive culture systems.

Aquaculture, v.299, p.89-98, 2010.

SAMOCHA, T.M.; PATNAIK, S.; SPEED, M.; ALI, A.M.; BURGER, J.M.; ALMEIDA, R.V.; AYUB, Z.; HARISANTO, M.; HOROWITZ, A.; BROCK, D.L. Use of molasses as carbon source in limited discharge nursery and grow-out systems for Litopenaeus vannamei. Aquacultural Engineering, v.36, p.184-191, 2007.
WIDANARNI; EKASARI, J.; MARYAM, S. Evaluation of biofloc technology application on water quality and production performance of red tilapia Oreochromis sp. cultured at different stocking densities. HAYATI Journal of Biosciences, v.19, n.2, p.73-80, 2012.

YANBO, W.; WENJU, Z.; WEIFEN, L.; ZIRONG, X. Acute toxicity of nitrite on tilapia (Oreochromis niloticus) at different external chloride concentrations. Fish Physiology and Biochemistry, v.32, p.49-54, 2006.

Data de recebimento: $26 / 08 / 2015$

Data de aprovação: 04/11/2015 